\title{
The Review of Powder Coatings
}

\author{
Zhongyan Du, Shaoguo Wen*, Jihu Wang, Changle Yin, Dayang Yu, Jian Luo \\ College of Chemistry and Chemical Engineering, Shanghai University of Engineering Science, Shanghai, China \\ Email: zhongyan_du@163.com, "sg_wen@qq.com
}

Received 25 January 2016; accepted 26 March 2016; published 29 March 2016

Copyright (C) 2016 by authors and Scientific Research Publishing Inc.

This work is licensed under the Creative Commons Attribution International License (CC BY).

http://creativecommons.org/licenses/by/4.0/

(c) (i) Open Access

\begin{abstract}
With the environmental regulations becoming more stringent and awareness of consumers increasing to protect environment, an urgent problem is to reduce the use of volatile organic compounds (VOCs). Powder coating is a kind of solid powder coating without any solvent. Due to its excellent application performance and environment-friendly, it is widely used in the field of metal coating, especially appliances of offices and home. In recent years, the use of powder coatings has been developed very fast and the requirements of functional powder coatings are also gradually strengthened. According to resin of the film forming, powder coatings can be divided into two types: thermosetting powder coatings and thermoplastic powder coatings. Each kind of powder coatings has its own advantages and disadvantages, and they will be applied in different fields. In order to improve the properties of powder coatings, there are many reports and studies about them. The compositions of powder coatings were extruded, crushed and screened to gain powder of coating. The powder always was stored at room temperature. The powder coatings often operated by two kinds which were electrostatic spraying method and fluidized bed dipping method. After that, the powder was heated to melt and cure. Finally, a smooth bright permanent film on articles was formed to achieve the purpose of decoration and corrosion. The process flow preparation of powder coatings always separated into dry process production and wet process production. The development courses of powder coatings about resins, pigments and fillers are summarized. The future development trends of powder coatings are illustrated.
\end{abstract}

\section{Keywords}

Powder Coatings, Classification, Process Flow of Preparation, Research Progress

\section{Introduction}

Powder coating is a $100 \%$ solids coating applied as a dry powder and subsequently formed into a film with heat. Its application method is that utilizes solid binder and pigment. The solid binder melts upon heating, binds the

*Corresponding author. 
pigment and results in a pigment coating upon cooling.

With health, safety, and environmental regulations within the industrial finishing industry stringent increasing, people are becoming more and more eco-friendly conscious in the coating field. This has led to an urgent need to reduce the use of volatile organic compounds (VOCs). However, the conventional organic coatings include a wide variety of VOCs, such as hydrocarbons (hexane, toluene, xylene), ketones (acetone, MEK, MIBK), alcohols (methanol, ethanol, cyclohexanol), and esters (ethyl acetate, butyl acetate, isobutyl acetate). In the applications of coating, substrates are strongly impacted by the recent regulatory constraints REACH (Registration, Evaluation, Authorization \& restriction of Chemicals) which aim to eliminate hazardous products, and to limit VOCs.

Those have caused coatings formulators to entire attention center on the development of technologies that meet the dual requirements of environmental compliance and excellent performance. Powder coatings present several advantages including little or no volatile organic content, high utilization rates, energy savings, environmental attributes, economic benefits and performance advantages and elimination of hazardous waste. As a result, powder coatings are enjoying high growth as industrial finishers look for ways to meet these challenges. In the past decades, there have been many significant changes in the coatings industry. There is a great demand of research work in this field, due to the commercial success and growing popularity of powder coatings [1]-[4].

\section{Classifications of Powder Coatings}

According to resin of powder coatings, there are two main coating systems, namely thermoplastic and thermosetting systems. Thermosetting powder coatings are made of thermosetting resin, curing agent, pigment, filler, and additives. Thermoplastic powder coating is made of thermoplastic resin, pigment, filler, plasticizer and stabilizer.

The thermosetting coatings are epoxy resin, polyester resin and acrylic resin along with various hardeners. Epoxy resin powder coating has excellent properties, as corrosion resistance, hardness, flexibility and impact strength. Due to polyester resin with polar groups, the polyester resin powder rate is high gloss, good flow, and good decorative. Acrylic resin powder coating has the advantages of good weather resistance, color retention, pollution resistance, strong metal adhesion, excellent film appearance, suitable for decorative powder coating.

The thermoplastic coatings are typically polyethylene, polyamide, polyvinyl chloride, and polyvinylidene fluoride. The polyethylene powder coating has excellent corrosion resistance, excellent electrical insulation and ultraviolet radiation. Polyamide powder coating has the advantages of high mechanical strength, impact resistance, hardness, low vacuum and so on. Polyvinyl chloride powder coating has excellent solvent resistance, good corrosion resistance, impact resistance, salt spray, can prevent food pollution and high insulation strength of electrostatic spraying. Poly trifluorovinyl chloride is cheap, better corrosion resistance than that of acid resistant enamel resistance, resistance to hydrochloric acid, dilute sulfuric acid, hydrogen chloride and chlorine corrosion resistance [5] [6].

\section{Manufacturing Process and Coating Process}

\subsection{Manufacturing Process}

The manufacturing of powder coatings was different from other kinds of coatings. Resin, pigment, filler, curing agent and other additives were mixed in certain proportion. Then the compositions was extruded, crushed and screened to gain powder of coating. The powder always was stored at room temperature. The powder coatings often operated by two kinds that electrostatic spraying method applied for thermoset powder coatings and fluidized bed dipping method used for thermoplastic powder coatings. After that, the powder was heated to melt and cure. Finally, a smooth bright permanent film on articles was formed to achieve the purpose of decoration and corrosion. There are two methods for the production of powder coatings, such as dry process production and wet process production, as shown in Table 1.

Each formulation consisting of resin, pigment, extender and other raw materials were mixed separately in a high-speed mixer operated. In the process of producing powder coatings, we often use the melt mixing method, and the concrete production diagram is shown in Figure 1. 


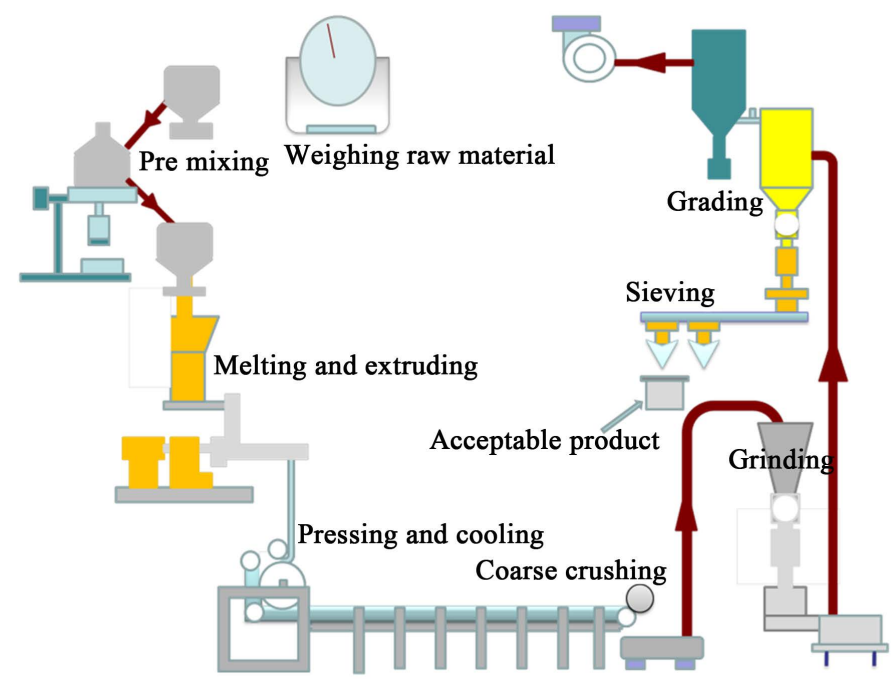

Figure 1. The concrete production diagram of melt mixing method.

Table 1. Manufacturing process of powder coating.

\begin{tabular}{|c|c|c|c|}
\hline \multirow{6}{*}{$\begin{array}{l}\text { Manufacturing } \\
\text { process of } \\
\text { powder coating }\end{array}$} & \multirow{3}{*}{$\begin{array}{l}\text { Dry process } \\
\text { production }\end{array}$} & Dry mixing method & raw material mixing $\rightarrow$ crushing $\rightarrow$ sieving $\rightarrow$ product \\
\hline & & Melt mixing method & $\begin{array}{l}\text { raw material mixing } \rightarrow \text { melt mixing } \rightarrow \text { cooling } \rightarrow \text { crushing } \rightarrow \\
\text { fine crushing } \rightarrow \text { sieving } \rightarrow \text { product }\end{array}$ \\
\hline & & Supercritical fluid method & $\begin{array}{l}\text { raw material mixing } \rightarrow \text { supercritical fluid } \rightarrow \\
\quad \text { spray granulation } \rightarrow \text { grading } \rightarrow \text { product }\end{array}$ \\
\hline & \multirow{3}{*}{$\begin{array}{l}\text { Wet process } \\
\text { production }\end{array}$} & Evaporation method & $\begin{array}{l}\text { the preparation of solvent based coatings } \rightarrow \text { evaporation or } \\
\text { vacuum extraction solvent } \rightarrow \text { crushing } \rightarrow \text { grading } \rightarrow \text { product }\end{array}$ \\
\hline & & Precipitation method & $\begin{array}{l}\text { the preparation of solvent based paint } \rightarrow \text { grinding } \rightarrow \text { mixing } \rightarrow \text { adding } \\
\text { precipitant into grain crushing } \rightarrow \text { sieving } \rightarrow \text { grading } \rightarrow \text { product }\end{array}$ \\
\hline & & The spray drying method & $\begin{array}{c}\text { the preparation of solvent based paint } \rightarrow \text { grinding } \rightarrow \text { mixing } \rightarrow \text { spray } \\
\text { drying } \rightarrow \text { products }\end{array}$ \\
\hline
\end{tabular}

\subsection{Coating Process}

In 1930s, flame spraying had opened the prelude of powder coatings which ensured polyethylene polymer (undissolved in solvent) and metal coating successfully applying. In 1952, Gemmer Company invented the technology of fluidized bed coating and the first generation of thermosetting pure epoxy powder coating was born in the end of the 1950s by the United States. Then, with the melt extrusion machine and electrostatic spraying technology appearing in 1961, powder coating began to enter the high-speed development stage.

There are two coating processes groups of powder coating. The most widely used method for a thermoplastic system is the fluidized bed process. Here, a hot metal test piece is dipped into fluidized powder. Another process for thermosetting products is predominately used with coating powders applying by electro static processes [5].

\section{The Research Progress of Powder Coatings}

\subsection{Research Progress of Resin}

The traditional resin cannot meet industry needs that recently a lot of researches were to carry out the modification of the traditional resin. Adding functional groups on the resin matrix could achieve the required performance. Dogan E. et al. [6] has proved that the glass transition temperature of carboxyl terminated oligomers can be increased by increasing the molecular weight but without sacrificing the reactive group concentration. This approach is important that acid number and glass transition temperature for powder coatings may potentially be used in the design of new carboxyl functional base resins. In order to higher the wetting angles, roughness values and abrasion resistance while decreased surface free energy values, Pilch-Pitera B. [7] has synthesized blocked polyisocyanate cross linkers for powder coatings. In the interest of improving hydrophobic properties, 
Vasil'ev V. A. et al. [8] has synthesized of a series of new epoxy oligomers with per fluorinated fragments $\mathrm{C}_{8} \mathrm{~F}_{17}$ was developed and implemented by a series of reaction. It was found that the synthesized products can be used as modifiers for epoxy powder composition for production of coatings. Jia X. et al. [9] has researched that liquid carboxyl-terminated poly (butadiene-co-acrylonitrile) (CTBN)-epoxy resin (EP) pre-polymers were prepared with different contents of CTBN. The experimental results demonstrate the ability of CTBN-EP pre-polymers, toughening technology to dramatically enhance the flexibility and impact resistance of FBE coatings without compromising other key properties such as corrosion protection.

\subsection{Research Progress of Pigment}

Pigment is an important part of powder coatings, choosing the right pigment to achieve the desired effect while the most important properties of the pigment are good dispersion and thermal stability. Pigment is often divided into inorganic pigment and organic pigment. Titanium dioxide is a kind of pigment often used in powder coatings. There is an investigation that the surface of nano- $\mathrm{TiO}_{2}$ is grafted with hydrophobic groups that the hydrophobicity was enhanced, which benefited their dispersion in coating matrix. Shi Q. et al. [10] has studied the polyester powder coating which was modified by 2 mass $\%$ of nano- $\mathrm{TiO}_{2}$. The results revealed that, the addition of nano- $\mathrm{TiO}_{2}$ made a delay of the melting point, and the starting and peak temperatures of curing reaction of the nano- $\mathrm{TiO}_{2}$ modified system were decreased by more than $5^{\circ} \mathrm{C}$. Adding 2 mass $\%$ of nano- $\mathrm{TiO}_{2}$ into polyester powder coatings has played a prompting role in the curing process. Hadavand B. S. et al. [11] has studied powder coating nano-ZnO with antibacterial properties. Surface of was successfully modified with VTMS. The results showed that the thermal stability of modified nano-ZnO has excellent compatible in blending process and good dispersion in polymeric matrix. The antibacterial experiments showed that the efficiency of coatings containing modified nano-ZnO is more than unmodified ones. In order to increase the ohmic conductivity of the resin system and change the mobile charge carriers, Trottier E. C. et al. [12] has applied the zinc oxide and silica as pigments into the epoxy polyester resin system. The results were that the resin matrix was opened; the activation energy for dipole rotation was lowered; the frequency of the relaxation peaks was shifted to lower; the Tg of the powder coating was increased by adding pigments. Puig M. et al. [13] has studied powder coating formulation with different contents of ZMP were applied over galvanized steel. The anticorrosive properties were studied by means of electrochemical methods. The different results showed that for this type of powder coating, the anticorrosive properties were enhanced when $10 \%$ or $15 \%$ ZMP was added due to the barrier properties improvement and the inhibitive action of the pigment. No variation in anticorrosive properties between samples $10 \%$ ZMP and 15\% ZMP was detected in salt fog spray test. Phosphate pigments are considered highly effective, safe corrosion inhibitors in various coating applications. The study of El-Ghaffar M. A. A. et al. [14] is to formulate anti-corrosive hybrid epoxy/polyester and polyester powder coating composites based on phosphate pigments. The prepared powder coating composites were applied on a cold rolled steel panels and were investigated for physico-mechanical properties and evaluated for their corrosion protection properties via salt spray chamber for $1000 \mathrm{~h}$. The obtained results showed high performance anti-corrosive powder coatings formulations for steel protection. There is no characteristic change in the physical and mechanical properties of the films.

\subsection{Research Progress of Filler}

As we known, filler is not only to increase the thickness but also improve the durability, hardness and other properties of the powder coatings film. Of course, different filler has different properties. Grigoriev A. Y. et al. [15] has proved the hardness of the friction surface of the composites depends on the susceptibility of the filler metals to strain hardening and explained differences in the values of their wear. They researched the tribological properties of PA-6 and PA-6 with surface layers gradient-filled with tin, lead, and bismuth nano-films in a concentration of up to $1.2 \mathrm{wt} \%$ which based coatings. Vähä-Nissi M. [16] has investigated the porosity and average pore size that compared the powders with a similar polymer to $\mathrm{CaCO}_{3}$ ratio to in conventional paper coatings. The study evaluated the feasibility of using highly filled powders with 100 parts per weight of calcium carbonate and 10 parts per-weight of polymer, acting as binder. In order to decrease energy consumption during the curing process while increasing a noticeable of the adhesion and hardness properties. Kalaee M. et al. [17] has set out to investigate the catalytic effect of $\mathrm{nCaCO}_{3}$ on the cure reaction of polyester/epoxy powder coatings. The effect of stearic acid coated $\mathrm{CaCO}_{3}$ nanoparticles on the morphology, cure behavior, adhesion and hardness properties of the polyester/epoxy blend powder coatings is very well. There is a study [18] that evaluated the scratch and 
wear performance of two thermosetting powder coatings with different weight fractions of filler. The filler is $\mathrm{MoS}_{2}$ solid lubricant, and it has a great scratch resistance response based the epoxy composite coatings than based the polyester composite. Piazza D. et al. [19] has investigated the properties of powder coatings that epoxy/MMT particles nano-composites with intercalated structures compared with epoxy/barium sulfate micro-composites. The result is epoxy/MMT particles presented better anticorrosion and physical properties than epoxy/barium sulfate micro-composites. They also found the organic coatings with higher thermal stability, good adhesion, barrier and thermal properties when added MMT into the epoxy matrix. These good performances are in virtue of the MMT has good dispersion and good interaction with the epoxy matrix. The type and volume fraction of the filler particles also effect on various properties of the coatings. Mirabedini S. M. et al. [20] has studied novel filler, HDK fumed silica nanoparticles, applying in powder coating. HDK fumed silica nanoparticles has increased the tensile strength, elastic modulus, hardness, energy to break and adhesion strength of the coating due to better dispersion and chemical interactions of nanoparticles/polymeric matrix. Nowadays, the filler with multi-functional performance has become a further development to meet the requirements the high quality coatings. Puig M. et al. [21] has studied organo-modified silica particles with silanes (OSP) in a polyester powder coating as an adhesion promoter. The results show that organo-modified silica particles not only improve the adhesion properties, but also corrosion protection of the coatings.

\section{Development of Powder Coatings}

With the development of the application field, the powder coatings will be moving towards the next few points.

- Micro-fine powder

Powder coatings have excellent flow ability due to micro-fine powder that creates a good construction conditions.

- Energy conservation

Both forming temperatures of film of thermoplastic and thermosetting powder coatings were about $180^{\circ} \mathrm{C}$ $200^{\circ} \mathrm{C}$, what is more, some forming temperatures reach to $350^{\circ} \mathrm{C}$. Energy consumption is large, so energy saving is emergency. Countries are committed to developing low temperature or room temperature curable powder coatings.

- Functional development of new varieties

The coating has a specific function after adding the corresponding modification substances such as antibacterial, deodorant.

- New technology and new equipment development continuum

VAMP US Ferro developed method is a method of manufacturing the revolutionary powder coating. Paint spraying robot has become a reality to convey continued powder coatings. The high degree of automation, continuous production process and equipment will be more widely used.

\section{References}

[1] Dumain, E.D., Agawa, T., Goel, S., et al. (1999) Cure Behavior of Polyester-Acrylate Hybrid Powder Coatings. Journal of Coatings Technology, 71, 69-75. http://dx.doi.org/10.1007/BF02697908

[2] Iwamura, G., Agawa, T., Maruyama, K., et al. (2000) A Novel Acrylic/Polyester System for Powder Coatings. Surface Coatings International, 83, 285-288. http://dx.doi.org/10.1007/BF02692728

[3] Takeshita, Y., Sawada, T., Handa, T., et al. (2012) Influence of Air-Cooling Time on Physical Properties of Thermoplastic Polyester Powder Coatings. Progress in Organic Coatings, 75, 584-589. http://dx.doi.org/10.1016/j.porgcoat.2012.07.003

[4] Lafabrier, A., Fahs, A., Louarn, G., et al. (2014) Experimental Evidence of the Interface/Interphase Formation between Powder Coating and Composite Material. Progress in Organic Coatings, 77, 1137-1144. http://dx.doi.org/10.1016/j.porgcoat.2014.03.021

[5] Takeshita, Y., Sawada, T., Handa, T., et al. (2012) Influence of Air-Cooling Time on Physical Properties of Thermoplastic Polyester Powder Coatings. Progress in Organic Coatings, 75, 584-589. http://dx.doi.org/10.1016/j.porgcoat.2012.07.003

[6] Dogan, E. and Acar, A.E. (2013) The Use of Anhydride Linkages to Increase the Glass Transition Temperatures of Polymers Containing Carboxyl End Groups: A Perspective in Powder Coatings. Progress in Organic Coatings, 76, 513-518. http://dx.doi.org/10.1016/j.porgcoat.2012.11.007 
[7] Pilch-Pitera, B. (2013) Blocked Polyisocyanates Containing Monofunctional Polyhedral Oligomeric Silsesquioxane (POSS) as Crosslinking Agents for Polyurethane Powder Coatings. Progress in Organic Coatings, 76, 33-41. http://dx.doi.org/10.1016/j.porgcoat.2012.08.008

[8] Vasil'ev, V.A., Korolev, I.V. and Mashlyakovskii, L.N. (2014) Effect of Molecular Structure of Epoxy Oligomers with Perfluorinated Fragments on Hydrophobic Properties of Powder Coatings. Russian Journal of Applied Chemistry, 87, 656-663. http://dx.doi.org/10.1134/S1070427214050218

[9] Jia, X., Zhang, S. and Liu, R. (2012) Preparation and Characterization of Carboxyl-Terminated Poly(butadiene-coacrylonitrile)-Epoxy Resin Prepolymers for Fusion-Bonded-Epoxy Powder Coating. Journal of Wuhan University of Technology, 27, 694-701.

[10] Shi, Q., Huang, W., Zhang, Y., et al. (2011) Curing of Polyester Powder Coating Modified with Rutile Nano-Sized Titanium Dioxide Studied by DSC and Real-Time FT-IR. Journal of Thermal Analysis and Calorimetry, 108, 1243-1249. http://dx.doi.org/10.1007/s10973-011-1855-4

[11] Hadavand, B.S., Ataeefard, M. and Bafghi, H.F. (2015) Preparation of Modified Nano ZnO/Polyester/TGIC Powder Coating Nanocomposite and Evaluation of Its Antibacterial Activity. Composites Part B: Engineering, 82, 190-195. http://dx.doi.org/10.1016/j.compositesb.2015.08.024

[12] Trottier, E.C., Affrossman, S. and Pethrick, R.A. (2012) Dielectric Studies of Epoxy/Polyester Powder Coatings Containing Titanium Dioxide, Silica, and Zinc Oxide Pigments. Journal of Coatings Technology and Research, 9, 525-539. http://dx.doi.org/10.1007/s11998-012-9405-y

[13] Puig, M., Gimeno, M.J., Gracenea, J.J., et al. (2014) Anticorrosive Properties Enhancement in Powder Coating Duplex Systems by Means of ZMP Anticorrosive Pigment. Assessment by Electrochemical Techniques. Progress in Organic Coatings, 77, 1993-1999. http://dx.doi.org/10.1016/j.porgcoat.2014.04.031

[14] El-Ghaffar, M.A.A., Abdel-Wahab, N.A., Sanad, M.A., et al. (2015) High Performance Anti-Corrosive Powder Coatings Based on Phosphate Pigments Containing Poly(o-aminophenol). Progress in Organic Coatings, 78, 42-48. http://dx.doi.org/10.1016/j.porgcoat.2014.09.021

[15] Grigoriev, A.Y., Kavaliova, I.N., Kupreev, A.V., et al. (2013) Friction and Wear of Polyamide-6 Powder Coatings Gradient-Filled by Metal Nanofilms. Journal of Friction and Wear, 34, 107-113. http://dx.doi.org/10.3103/S1068366613020050

[16] Vähä-Nissi, M. (2015) Characterization of Filled Powders for Powder Coating of Paper. Powder Technology, 279, 127-133. http://dx.doi.org/10.1016/j.powtec.2015.04.008

[17] Kalaee, M., Akhlaghi, S. and Nouri, A. (2011) Effect of Nano-Sized Calcium Carbonate on Cure Kinetics and Properties of Polyester/Epoxy Blend Powder Coatings. Progress in Organic Coatings, 71, 173-180. http://dx.doi.org/10.1016/j.porgcoat.2011.02.006

[18] Zouari, M., Kharrat, M., Dammak, M., et al. (2015) Scratch Resistance and Tribological Performance of Thermosetting Composite Powder Coatings System: A Comparative Evaluation. Surface and Coatings Technology, 263, 27-35. http://dx.doi.org/10.1016/j.surfcoat.2014.12.066

[19] Piazza, D., Lorandi, N.P., Pasqual, C.I., et al. (2011) Influence of a Microcomposite and a Nanocomposite on the Properties of an Epoxy-Based Powder Coating. Materials Science and Engineering: A, 528, 6769-6775. http://dx.doi.org/10.1016/j.msea.2011.05.062

[20] Mirabedini, S.M. and Kiamanesh, A. (2013) The Effect of Micro and Nano-Sized Particles on Mechanical and Adhesion Properties of a Clear Polyester Powder Coating. Progress in Organic Coatings, 76, 1625-1632. http://dx.doi.org/10.1016/j.porgcoat.2013.07.009

[21] Puig, M., Cabedo, L., Gracenea, J.J., et al. (2014) Adhesion Enhancement of Powder Coatings on Galvanised Steel by Addition of Organo-Modified Silica Particles. Progress in Organic Coatings, 77, 1309-1315. http://dx.doi.org/10.1016/j.porgcoat.2014.03.017 